REVIEW

\title{
Excess in cardiovascular events on Mondays: a meta- analysis and prospective study
}

\author{
Adrian G Barnett, Annette J Dobson
}

J Epidemiol Community Health 2005;59:109-114. doi: 10.1136/jech.2003.019489

The aim of this paper was to summarise the reported excess in coronary events on Mondays, and examine the evidence for three competing explanations: stress, alcohol consumption, or registration errors. A review of the literature found 28 studies covering 16 countries and over 1.6 million coronary events. The overall Monday excess was small; in a population experiencing 100 coronary events per week there was one more event on Monday than other days. The excess was larger in men and in studies including sudden cardiac death or cardiac arrests. In a prospective study an increase in events on Mondays was associated with greater alcohol consumption, lower rainfall, and the month of January. The excess in coronary events on Mondays is a persistent phenomenon. The size of the effect varies widely between populations. There is some evidence of an association with alcohol consumption, but a definitive explanation remains elusive and is likely to remain so because of the smallness of the effect and the paucity of high quality data.

See end of article for authors' affiliations

.....................

Correspondence to: Dr A G Barnett, School of Population Health, University of Queensland, Herston, QLD 4006,

Australia; a.barnett@sph. uq.edu.au

Accepted for publication 23 April 2004
$\mathrm{R}$ ates of coronary heart disease (CHD) vary over the day, the week, and the year. ${ }^{1}$ A decrease in risk at night and increase in the morning is thought to be attributable to tachycardia and an increase in blood pressure after waking. The size of the effect has been estimated as a $40 \%$ increase in events in the morning ( 6 am to noon) compared with the rest of the day. ${ }^{2}$ An increase in coronary events in colder months and decrease in warmer months has been linked to changes in the weather. ${ }^{3}$ For example, in Ireland a $45 \%$ increase in cardiovascular deaths was observed in winter compared with summer. ${ }^{4}$ The weekly variation of an increase on Monday has yet to be convincingly explained, nor has the size of the effect been adequately described. Some hypothesised reasons for this variation include:

(1) an increase in stress on Mondays in employed people $^{5}$

(2) weekend alcohol consumption (because high use may cause arrhythmias and thrombo$\operatorname{sis}^{6}{ }^{7}$ )

(3) anomalies in data registration. ${ }^{8}$

All, some, or none of these hypotheses may be correct. To investigate them further-and to clarify the size of the excess - we first summarise the existing findings of the Monday excess.
Differences among studies may be useful for identifying the real cause (or causes) of the Monday excess. " If the hypotheses of alcohol consumption or stress were true, then we would expect the differences between studies to be attributable to study populations. If the excess was caused by data collection and recording procedures then the differences between studies should be related to study design and methods.

To date no individual study has simultaneously investigated the three hypotheses. We attempt to do this using a prospective community based study of coronary events, conducted as part of the WHO MONICA Project (to monitor trends and determinants in cardiovascular disease). ${ }^{10}$

\section{METHODS}

Meta-analysis

We followed the meta-analysis guidelines for observational studies given by the MOOSE group. ${ }^{11}$

We searched the databases of Medline, Pubmed, the Cochrane Library, and Web of Science using combinations of the words "Monday", "Hebdomadal", "Cardiovascular", and "Infarction". The search had no time period restriction. For every relevant publication we searched all related references. We contacted three authors of relevant publications about other work in the area, but this did not yield any extra studies. Two studies (one German, one Italian) were translated into English. One paper was an abstract. ${ }^{12}$

\section{Prospective study}

In this study we used data from the MONICA centre in Newcastle, Australia. ${ }^{13}$ The study population was adults age 25-69 years living in the Hunter Region of New South Wales; this is a temperate area on the east coast, with a mixed economy of manufacturing, mining, and agriculture. Ethical approval for the study was obtained from the University of Newcastle and Hunter Region Health Service Ethics Committees.

All suspected CHD events in the study population were identified prospectively from surveillance of hospital admissions, death records, and other sources. Those events confirmed as eligible were added to the coronary register.

The date of coronary event onset was recorded as the day symptoms began. Instructions were

Abbreviations: CHD, coronary heart disease; $S C D$, sudden cardiac death; CVD, cardiovascular disease 
Table 1 Summary of studies presenting results on the weekly distribution of fatal coronary events, ordered by total number of events

\begin{tabular}{|c|c|c|c|c|c|c|c|}
\hline Reference & Population(s) & Period & $\begin{array}{l}\text { Diagnostic } \\
\text { category }\end{array}$ & $\begin{array}{l}\text { Number of } \\
\text { events }(N)\end{array}$ & $\begin{array}{l}\text { Days with a } \\
\text { significant excess }\end{array}$ & $\begin{array}{l}\text { Monday } \\
\text { excess } \hat{M} \%\end{array}$ & $95 \% \mathrm{Cl}$ \\
\hline Rogot & USA & $1962-66$ & $\mathrm{CHD}$ & $>2$ million & Monday* & NA & \\
\hline AlHW & Australia & 1979-99 & Acute MI & 429255 & Monday & 2.0 & 1.3 to 2.8 \\
\hline Macfarlane & England and Wales & 1969-72 & Acute MI & 373598 & Monday & 3.2 & 2.4 to 4.0 \\
\hline Evans & Scotland & 1986-95 & CHD & 170244 & $\begin{array}{l}\text { Monday, } \\
\text { Saturdayt, } \\
\text { Sunday }\end{array}$ & 3.1 & 1.9 to 4.3 \\
\hline Chenet, 1998 & Moscow & 1993-95 & CVD & 117286 & $\begin{array}{l}\text { Monday } \ddagger \text {, } \\
\text { Saturday } \neq \\
\text { Sunday } \neq\end{array}$ & 0.8 & -0.6 to 2.2 \\
\hline Näyhä & Finland & 1961-72 & IHD & 113246 & $\begin{array}{l}\text { Monday, } \\
\text { Saturday }\end{array}$ & 3.4 & 2.0 to 4.8 \\
\hline Massing & Saxony, Germany & 1968-77 & $\mathrm{MI}$ & 84538 & $\begin{array}{l}\text { Monday§, } \\
\text { Saturday§ }\end{array}$ & 0.8 & -0.9 to 2.4 \\
\hline Barnett & 39 centres worldwide & 1980-95 & MI & 74068 & Monday & 6.8 & 5.0 to 8.6 \\
\hline Chenet, 2001 & Lithuania & 1988-97 & CVD and IHD & 41452 & $\begin{array}{l}\text { Monday, } \\
\text { Saturday, } \\
\text { Sunday }\end{array}$ & 9.7 & 7.3 to 12.2 \\
\hline Arntz & Berlin & 1987-91 & SCD & 24061 & Monday & 8.3 & 5.1 to 11.5 \\
\hline Macfarlane & Greater London & $1965-66$ & IHD & 22813 & Monday & 4.0 & 0.8 to 7.2 \\
\hline Beard & Rochester, USA & $1950-75$ & SCD & 1054 & None & -3.0 & -17.6 to 11.6 \\
\hline Pasqualetti & Aquila, Italy & $1970-87$ & SCD & 269 & None & 24.9 & -7.1 to 56.9 \\
\hline Myers & Newcastle, UK & 1971-72 & $S C D$ & 100 & None & 26.0 & -26.7 to 78.7 \\
\hline Nicolau & Bucharest & 1981-84 & CVD & 86 & Monday & 70.9 & 7.4 to 134.5 \\
\hline
\end{tabular}

CHD, coronary heart disease; CVD, cardiovascular disease; IHD, ischaemic heart disease; MI, myocardial infarction; SCD, sudden cardiac death; NA, not available. *No statistical testing done but numbers involved make it highly likely that observed increase is statistically significant. $†$ Subgroup of $C H D$ deaths outside hospital in men under 65 years old. $¥$ Subgroup of men $(N=69934)$. $\S$ Subgroup of men age $25-54$ years $(N=6259)$. $~ N$ Number of events estimated from graphical results.

also given to code the day as missing if the date was uncertain, or there was a vague onset and a slow increase in severity of symptoms over several days, that is a crescendo onset. If the subject was found dead circumstantial evidence was used to estimate the day of death. Subjects were interviewed soon after the event; if the subject had died then information was obtained from relatives or other informants.

We used employment as a surrogate measure of stress. We assumed that people in part time or full time employment were more likely to be stressed on Mondays than those who were unemployed, retired, studying, engaged in home duties, or unable to work. The employment question was not used during part of the registration period, so only a subset of the total sample was available for this analysis.

The number of questionnaire responses that were missing or not known was used as an indicator of data quality. We assumed that more guessing of onset dates would take place where fewer details were available.

Because the weather may affect patterns of alcohol consumption, daily temperature and rainfall data were obtained from the Hunter Valley Research Foundation for 1985-90. We summarised both average daily temperature and total daily rainfall over the previous zero to three days to model the possible lag between exposure and onset of the coronary event.

Table 2 Summary of studies presenting results on the weekly distribution of non-fatal coronary events or both fatal and nonfatal events, ordered by total number of events

\begin{tabular}{|c|c|c|c|c|c|c|c|}
\hline Reference & Population(s) & Period & $\begin{array}{l}\text { Diagnostic } \\
\text { category }\end{array}$ & $\begin{array}{l}\text { Number of } \\
\text { events }(N)\end{array}$ & $\begin{array}{l}\text { Days with a } \\
\text { significant excess }\end{array}$ & $\begin{array}{l}\text { Monday } \\
\text { excess } \hat{M} \%\end{array}$ & $95 \% \mathrm{Cl}$ \\
\hline Barnett & 39 centres worldwide & 1980-95 & Non-fatal MI & 153305 & Monday & 9.2 & 7.9 to 10.5 \\
\hline Peters & $\begin{array}{l}32 \mathrm{~N} \text { American centres } \\
\text { and one Swedish }\end{array}$ & 1987-91 & Acute Ml & 22516 & Monday & 8.5 & 5.2 to 11.8 \\
\hline Gnecchi & Italy & 1988-89 & Acute MI & 11472 & Monday & 8.6 & 4.0 to 13.2 \\
\hline WHO & $\begin{array}{l}18 \text { European centres } \\
\text { and one Australian }\end{array}$ & 1971 & Acute Ml & 8502 & Saturday & 4.1 & -1.2 to 9.4 \\
\hline Allegra & New Jersey, USA & 1988-98 & Cardiac arrests & 6827 & Saturday & 5.1 & -0.8 to 11.0 \\
\hline Willich & Augsburg, Germany & $1985-90$ & Acute $\mathrm{MI}$ and SCD & 5596 & Monday & 11.8 & 5.1 to 18.5 \\
\hline Peckova & Seattle, USA & $1985-93$ & Cardiac arrests & 5248 & Monday & 8.0 & 1.2 to 14.9 \\
\hline Genès & France & 1995 & $\mathrm{Ml}$ & 2348 & None & -0.1 & -10.0 to 9.8 \\
\hline Thompson & Leicester, UK & 1979-88 & Acute MI & 2254 & $\begin{array}{l}\text { Monday, } \\
\text { Tuesday }\end{array}$ & 12.7 & 2.1 to 23.4 \\
\hline Spielberg & Dessau, Germany & 1980-88 & Acute MI & 1901 & Monday & NA & \\
\hline Bilora & Northern Italy & 1992 & Acute MI & 817 & Monday* & 4.5 & -12.6 to 21.6 \\
\hline Ku & Taipei & 1992-96 & Acute MI & 540 & Tuesday & 5.0 & -16.1 to 26.1 \\
\hline Zhou & China & 1991 & Acute MI & 428 & Saturday & -15.0 & -36.6 to 6.7 \\
\hline Rabkin & Canada & 1948-77 & SCD & 358 & Monday & 34.9 & 6.3 to 63.5 \\
\hline Paul & Boston, USA & NA & $\mathrm{Ml}$ & 334 & $\begin{array}{l}\text { Monday and } \\
\text { Tuesday } \\
\text { combined }\end{array}$ & $29.9+$ & 0.8 to 59.1 \\
\hline
\end{tabular}

MI, myocardial infarction; SCD, sudden cardiac death; NA, not available. *Subgroup of active workers $(N=264)$. †No results given for Monday alone, so an estimate of $\hat{M} \%$ was made by halving the combined results from Monday and Tuesday. 


\section{Statistical methods}

The excess in events on a Monday was defined as

$$
\hat{M} \%=100\left(\frac{m}{N}-\frac{1}{7}\right) / \frac{1}{7}
$$

where $m$ is the observed number of events on a Monday and $N$ is the total number of events over all days. The value $\hat{M} \%$ is the percentage of excess events on a Monday compared with the expected of proportion of $1 / 7$. Confidence intervals for the excess percentage of Monday events were calculated using the normal approximation to the binomial distribution.

\section{Meta-analysis}

The Monday excess was estimated using a random effect meta-analysis, ${ }^{14}$ and was implemented using the Bayesian WinBUGS software. ${ }^{15}$ Results using Bayesian methods are reported with a $95 \%$ posterior interval (PI), and results using standard methods are reported with a 95\% confidence interval $(\mathrm{CI})$. Both intervals estimate a probable range of the parameter of interest, but the PI has the simpler interpretation as an interval that has a high $(95 \%)$ probability of containing the true parameter value.

A test of heterogeneity between studies was performed using the $I^{2}$ statistic, $^{16}$ which is interpretable as the proportion of total variation in the Monday excess that is attributable to differences between studies; the remaining variation is attributable to random error.

To examine possible explanations of any differences between studies we used a regression tree ${ }^{17}$ analysis of the Monday excess. The study level explanatory variables were: data collection method (retrospective compared with prospective), study location (Eastern Europe compared with other-because excessive alcohol consumption is higher in Eastern Europe ${ }^{7}$ ), study time (midpoint in years), study duration (years and months), event outcome (fatal only compared with only non-fatal or both fatal and non-fatal), total number of events, and diagnostic category (see tables 1 and 2). Study time was used to examine any temporal trend in the Monday excess. Study duration was used as a proxy for quality, with shorter studies possibly having greater accuracy. Diagnostic category was not a precise grouping, but it did broadly differentiate the studies. There was probably some misclassification, for example, studies with a diagnostic category of CHD probably included some sudden deaths, and studies with a diagnostic category of sudden cardiac death probably included some unattended sudden deaths from myocardial infarction and other CHD. We classified study outcomes into five diagnostic groups: myocardial infarction (MI) or acute MI, sudden cardiac death (SCD), cardiac arrest, CHD or ischaemic heart disease (IHD), and cardiovascular disease (CVD). Because diagnostic category was a nominal explanatory variable with five categories we used a regression tree rather than standard regression analysis. The tree method evaluated every possible split of the five categories into two groups, while simultaneously evaluating the effect of the other covariates. We used 10-fold cross-validation to select an optimal tree. The tree analysis was run using the "rpart" library in R. ${ }^{18}$

\section{Prospective study}

The excess in events on a Monday was examined using equation (1). The distribution of events over the month was also examined to check for excesses on the 1st or 15th of the month that would indicate some systematic imputation of unknown onset dates. ${ }^{8}$

Univariate comparisons between either the missing and non-missing event dates, or Monday and non-Monday events were made using the $\chi^{2}$ test for categorical variables and the Wilcoxon two sample test for continuous variables.

We used multiple logistic regression to predict an event on a Monday using the explanatory variables of: age, sex, usual frequency and quantity of alcohol consumption, smoking status (non-smoker, ex-smoker, current smoker, unknown), history of previous MI, apparent survival time, average temperature and total rainfall (previous 0-3 days), month, year, and number of missing data items. Employment status was not used in the logistic regression because it was not collected throughout the study period. A model was chosen using a backward stepwise procedure (with a significance level of $10 \%$ ), and the regression diagnostics of Pregibon. ${ }^{19}$

\section{RESULTS}

\section{Meta-analysis: description of studies}

We found 28 community based studies ${ }^{5} 81220-43$ with results on the weekly distribution of CHD events. Two studies ${ }^{83}$ presented results in two populations, so there is a total of 30 results summarised in table 1 (fatal coronary events) and table 2 (non-fatal coronary events or both fatal and non-fatal events). The number of days after the onset of symptoms that a death would still be attributable was not always clearly defined, which may cause some inconsistency between studies.

Two studies ${ }^{44} 45$ were found that examined the Monday excess in a population at high risk of a coronary event, and hence were not included

With three exceptions, ${ }^{25}{ }^{35} 38$ the studies were retrospective and relied on routinely collected data such as death certificates or hospital records, although five studies 8122239 used a coronary event register that was updated close to the date of the event. Three studies ${ }^{12} 3135$ recruited subjects from admissions to an emergency department. The Moscow study ${ }^{36}$ reported results for cardiovascular deaths based on the Soviet classification system that may include stroke.

Table 3 Meta-analysis of excess Monday events and subgroup meta-analyses by gender (where available), diagnostic category, event category, and study size

\begin{tabular}{|c|c|c|c|c|c|c|}
\hline Category & Subgroup & $\begin{array}{l}\text { Number of } \\
\text { studies }\end{array}$ & $\begin{array}{l}\text { Number of } \\
\text { events }(N)\end{array}$ & $\begin{array}{l}\text { Amount of } \\
\text { heterogeneity* }\left(I^{2}\right)\end{array}$ & $\begin{array}{l}\text { Estimated } \\
\text { excess } \hat{M} \%\end{array}$ & $95 \% \mathrm{PI}$ \\
\hline \multirow[t]{2}{*}{ Gender } & Male & 14 & 656730 & 83.0 & 9.6 & 2.3 to 17.7 \\
\hline & Female & 12 & 331064 & 76.2 & 4.0 & -5.4 to 13.7 \\
\hline \multirow[t]{2}{*}{ Diagnostic category } & SCD and Cardiac arrest & 8 & 43513 & 24.6 & 11.6 & -3.3 to 27.4 \\
\hline & $\begin{array}{l}\mathrm{CHD} / \mathrm{IHD}, \mathrm{CVD} \\
\mathrm{Ml} \text {, acute } \mathrm{MI}\end{array}$ & 19 & 1628768 & 90.0 & 4.8 & -0.1 to 9.6 \\
\hline \multirow[t]{2}{*}{ Event category } & Fatal events only & 14 & 1452070 & 85.2 & 5.3 & -1.6 to 12.9 \\
\hline & Fatal and non-fatal events & 13 & 220211 & 31.6 & 7.1 & -0.6 to 15.1 \\
\hline Study size & Larger studies only $(N>400)$ & 23 & 1671468 & 88.6 & 4.9 & 1.1 to 8.7 \\
\hline All studies & & 27 & 1672281 & 87.3 & 5.9 & 2.0 to 9.9 \\
\hline
\end{tabular}

*The percentage of total variation in the Monday excess that is attributable to heterogeneity between studies. CHD, coronary heart disease; CVD, cardiovascular disease; IHD, ischaemic heart disease; MI, myocardial infarction; SCD, sudden cardiac death; PI, posterior interval; $N$, total number of events. 


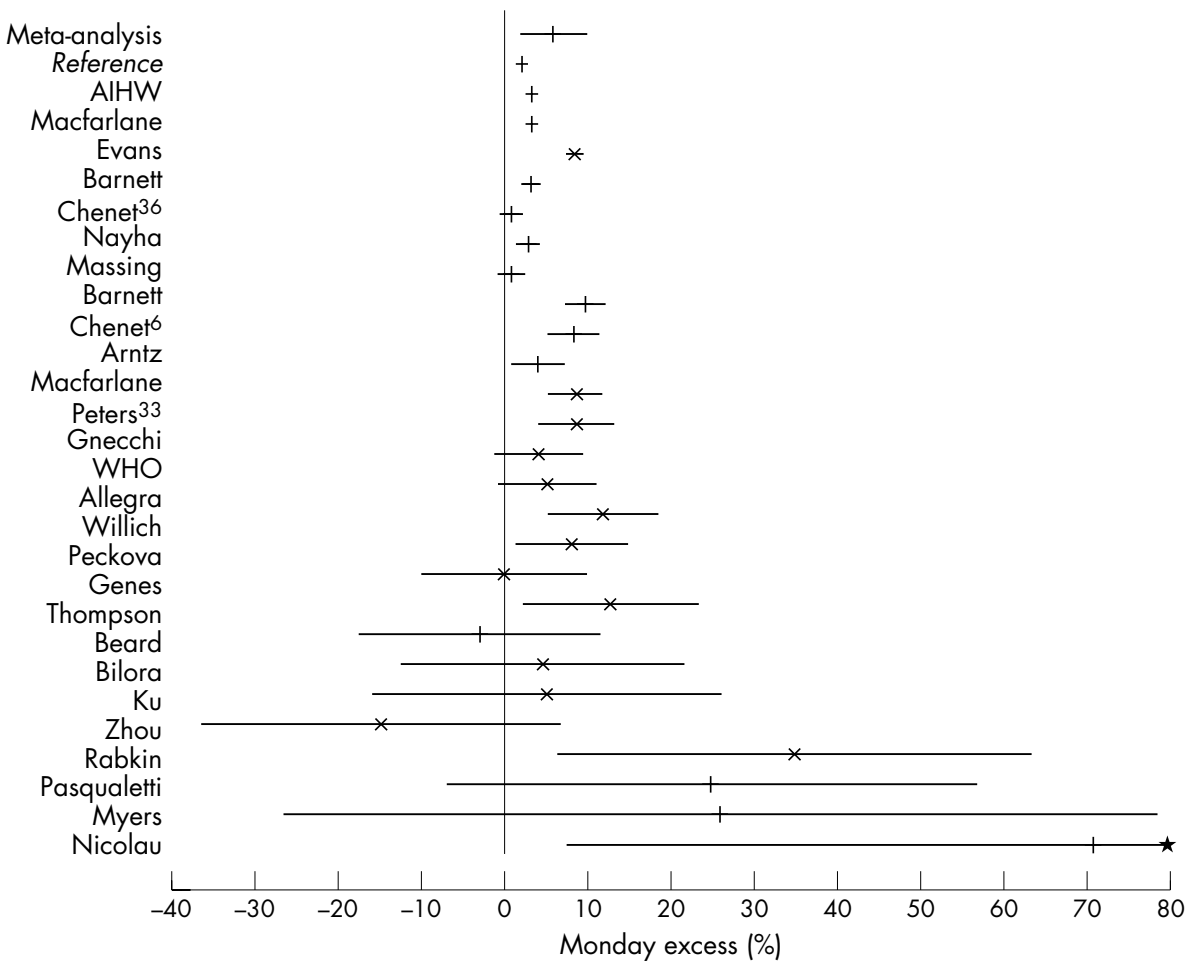

Figure 1 Meta-analysis of community based studies: overall and study specific estimates of the Monday effect. Studies are listed in order of the total number of events, for the exact $N$ see tables 1 and 2. The line at $M \%=0$ represents no excess. *Upper limit of $134.5 \%$ for smallest study ${ }^{29}$ not shown to improve the scale. Lines represent the mean estimate for studies reporting fatal events only, crosses represent the mean estimate for studies that included some non-fatal events.

A statistically significant excess in coronary events on Mondays was reported in 22 of the 30 results (and 20 of the 28 studies). Significant excesses in events were also found in some studies on Tuesday, Saturday, and Sunday. Only four studies reported no significant differences on any days. The excess in events on Mondays has been observed: in both fatal and non-fatal events; in both sexes; in the United States, Canada, Australia, and Europe; and in the 1960s, 70s, 80s, and 90s.

Table 4 Crude estimates of the Monday excess of events in key categorical variables in the prospective study

\begin{tabular}{|c|c|c|c|c|}
\hline Variable & Category & $\begin{array}{l}\text { Number of } \\
\text { events }(N)\end{array}$ & $\begin{array}{l}\text { Monday } \\
\text { excess* } \hat{M} \%\end{array}$ & p Value \\
\hline \multirow[t]{2}{*}{ Gender } & Male & 7669 & 3.2 & 0.98 \\
\hline & Female & 3720 & 3.4 & \\
\hline \multirow[t]{4}{*}{$\begin{array}{l}\text { Apparent survival } \\
\text { time }\end{array}$} & $\begin{array}{l}\text { Death } \\
<1 \text { hour }\end{array}$ & 1081 & 3.6 & 0.63 \\
\hline & $\begin{array}{l}\text { Death } \\
\geqslant 1 \text { hour }\end{array}$ & 1014 & 10.5 & \\
\hline & $\begin{array}{l}\text { Alive at } \\
28 \text { days }\end{array}$ & 8532 & 2.0 & \\
\hline & Unknown & 312 & 14.4 & \\
\hline \multirow[t]{3}{*}{ Employedł } & Yes & 1602 & 5.3 & 0.84 \\
\hline & No & 4428 & 5.8 & \\
\hline & Unknown & 289 & -3.1 & \\
\hline \multirow{6}{*}{$\begin{array}{l}\text { Usual frequency of } \\
\text { alcohol consumed } \\
\text { (days/week) } \\
\text { Usual quantity of } \\
\text { alcohol consumed } \\
\text { (number standard } \\
\text { drinks) }\end{array}$} & High $(>4)$ & 2134 & 15.1 & 0.040 \\
\hline & Low $(0-4)$ & 7875 & -0.2 & \\
\hline & Unknown & 930 & 5.4 & \\
\hline & High $(>8)$ & 753 & 7.8 & 0.51 \\
\hline & Low $(0-8)$ & 8651 & 1.9 & \\
\hline & Unknown & 1535 & 9.0 & \\
\hline \multirow[t]{3}{*}{ Binge drinking } & Yes & 176 & -24.4 & 0.22 \\
\hline & No & 9266 & 2.9 & \\
\hline & Unknown & 1497 & 9.0 & \\
\hline \multirow[t]{2}{*}{ Month } & January & 880 & 22.5 & 0.0017 \\
\hline & Other & 10059 & 1.6 & \\
\hline Overall & & 10939 & 3.3 & \\
\hline
\end{tabular}

${ }^{*} \hat{M} \%$ defined in equation (1), larger $\hat{M} \%$ indicates a greater excess in events on a Monday. $\uparrow \chi^{2}$ Test; $\ddagger N=6319$ as employment status was only available for a subset of questionnaires.
The Monday excess was shown to be greater in younger compared with older subjects in five studies (age $<65$ years, ${ }^{42}$ age $\leqslant 65,{ }^{40}$ age $<50,{ }^{41}$ men $<65,{ }^{24}$ men $\left.<60\right){ }^{23}$ An excess in both younger and older age groups was shown in three studies, ${ }^{52}{ }^{36}$ while one study ${ }^{33}$ reported that the excess was greater in the elderly population (age $>65$ years). It has been suggested that the excess at younger ages is attributable to employment status and therefore stress. ${ }^{23}{ }^{40}$ A significantly greater Monday excess in working compared with nonworking subjects was shown in two studies, ${ }^{51}$ but no statistically significant difference was found in another. ${ }^{33}$

A greater excess in Monday events in men than women was shown in two studies, ${ }^{23}{ }^{24}$ whereas one ${ }^{5}$ had a greater excess in women, and another ${ }^{33}$ found no statistically significant difference.

The Monday effect was shown to be larger in cardiovascular deaths outside hospital in Moscow ${ }^{36}$ and in a subgroup of coronary deaths occurring outside hospital in people with no previous admissions for CHD in Scotland. ${ }^{41}$ The authors of both papers suggested that the excess in deaths on Monday was attributable to binge drinking.

Using data from many centres in the WHO MONICA Project we showed that the Monday excess was greater in

Table 5 Distribution of continuous variables among those experiencing, and those not experiencing an event on Monday in the prospective study

\begin{tabular}{llll}
\hline Variable & Monday & Median & p Value* \\
\hline Age & Yes & 60 & 0.30 \\
& No & 61 & \\
Total rainfall† (mm) & Yes & 0.75 & 0.30 \\
(previous 0-3 days) & No & 0.90 & \\
Average temperature† ( $\left.{ }^{\circ} \mathrm{C}\right)$ & Yes & 23.4 & 0.23 \\
(previous 0-3 days) & No & 23.2 & \\
Number of missing & Yes & 1 & 0.54 \\
data items & No & 2 & \\
\hline
\end{tabular}

*Wilcoxon two sample test; $\uparrow N=5796$ as weather data were only available from 1985-90. 


\section{Key points}

- There is a small excess in cardiovascular events on Mondays in many populations worldwide. The excess seems highest in sudden cardiac deaths.

- Some evidence was found of an association with alcohol consumption, but a definitive explanation of the Monday effect remains elusive.

centres with less thorough data collection procedures, and fewer missing dates of coronary onset. ${ }^{8}$ Excesses of events of a similar size to the Monday excess were found on the first of the month, suggesting that when the date of onset was unknown, some centres imputed Monday or the first of the month rather than recording the date as missing.

\section{Meta-analyses: random effects and meta-regression models}

Three studies ${ }^{122134}$ were excluded from the meta-analysis as they did not report the total number of events or the number observed on a Monday, which are required for equation (1). Meta-analyses of the remaining studies based on over 1.6 million coronary events from 27 results are shown in table 3.

The estimated mean Monday excess was 5.9\% (95\% PI: $2.0 \%$ to $9.9 \%$ ) or an excess number of events on a Monday of 0.8 in a population experiencing 100 events per week $(95 \%$ PI: 0.3 to 1.4). Figure 1 shows a summary plot of the results. The studies are listed in order of total number of events, with a different marker if non-fatal events were included. The very large Monday excesses in the four smallest studies suggested a publication bias. To reduce the possible impact of publication bias we ran a meta-analysis using the 22 results each with more than 400 events and obtained an estimated Monday excess of $4.8 \%$ (95\% PI: $0.7 \%$ to $8.9 \%$ ).

The Monday excess was smaller for women than men. In women the excess was $4.0 \%$ (95\% PI: $-5.4 \%$ to $13.7 \%$ ), indicating a non-significant excess.

In the regression tree analysis only diagnostic category was selected by the optimal tree; the Monday effect was more apparent in studies of sudden cardiac death or cardiac arrest. In a subgroup meta-analysis of the eight studies with the outcome of SCD or cardiac arrest the Monday excess was $11.6 \%$ (95\% PI: -3.3 to 27.4 ).

The heterogeneity between the results was large, in the overall meta-analysis $87.3 \%$ of the total variation in the Monday excess was due to differences between studies. There was a much less heterogeneity between the results of studies that included non-fatal events and in studies of SCD or cardiac arrest.

\section{Prospective study}

A total of 11637 events was recorded between 1984 and 1994. We excluded 698 events $(6.0 \%)$ because the exact date of onset was incomplete. Compared with the events with a confirmed date these events were significantly more likely to be fatal, in older people, and have incomplete information on employment and alcohol consumption.

Of the 10939 coronary events with an exact onset date, 1614 occurred on Monday, giving an excess of 3.3\% (95\% CI: $-1.4 \%$ to $7.9 \%$ ), which is in the $95 \%$ PI of the meta-analysis. There was no significant excess in events on the 1st, 15th, or 30-31st of the month.

Crude associations between events on a Monday and various putative predictors are shown in tables 4 and 5; only alcohol consumption and the month of January showed a statistically significant association. January was specifically

\section{Policy implications}

The small excess in events on Mondays does not warrant any policy attention beyond the well established measures to reduce heart disease in general.

chosen as it showed a strong association in exploratory analyses. In binge drinkers fewer events were observed on Monday $(\hat{M} \%=-24.4 \%)$, although this was not statistically significant. In contrast more events occurred on Friday and Sunday in binge drinkers (Excess $>19 \%$ ), but again these differences were not significant because of the small total number of binge drinkers (results not shown).

In a multiple logistic regression model, events on a Monday were more likely to occur in January (OR $=1.36$, $95 \%$ CI: 1.06 to 1.75 ) and in periods with less rainfall $(\mathrm{OR}=1.027,95 \% \mathrm{CI}: 1.012$ to 1.043 , for a one millimetre decrease in total rainfall).

\section{DISCUSSION}

The meta-analysis showed that the Monday excess in coronary events is small but greater than zero. The excess on Mondays is less than 1 event in 100, or a relative increase of $1 \%$, whereas events in the morning have been shown to increase by $40 \%,{ }^{2}$ and in events in winter by $45 \% .{ }^{4}$

To investigate the cause of the excess we looked for differences in the published results that might be explained by study features. Differences in the size of the excess were found according to gender (greater in men) and diagnostic category (greater in studies of sudden cardiac death or cardiac arrests). The plot of study results (fig 1) suggested a publication bias, and when only large studies were considered the Monday excess reduced but remained statistically significant.

The link between binge drinking and heart disease is strongest in sudden cardiac deaths, ${ }^{46}$ and therefore the greater Monday excess in studies of sudden cardiac death provides support for the binge drinking hypothesis, and differences in the Monday excess among diagnostic categories explain some of the large variability in results. However, sudden cardiac deaths are also more likely to be unwitnessed, and hence the greater Monday excess found in studies of these events also supports the registration hypothesis.

We did find other evidence to support the hypothesis of binge drinking. Men generally consume more alcohol than women, which could explain their greater Monday excess in the meta-analysis. The prospective study found a direct association between high alcohol consumption and the Monday excess, but binge drinking was negatively associated. We also found associations between the Monday excess and January and low rainfall. Both these factors can be indirectly linked to alcohol consumption as in Australia January is a hot month traditionally devoted to summer holidays with a high incidence of social drinking. Additionally alcohol consumption and high temperatures may interact to increase the risk of a coronary event. ${ }^{47}$ These associations with the Monday excess, and the large variation in the Monday excess in the meta-analysis, suggest that there may be populations in which the Monday effect may be important.

Apart from the link with sudden cardiac deaths we found little evidence to support the registration hypothesis. If this hypothesis were true we would have expected a greater excess in fatal events on Mondays, because the date of onset might be unknown for unwitnessed deaths (and these events could have had the date of onset imputed as Monday). In fact 
there was a slightly greater Monday excess in non-fatal events. Similarly, we would have expected retrospective studies to have less accurate onset dates and hence have a higher proportion of Monday events; this was not the case. Furthermore, the prospective analysis showed no difference in the Monday excess according to the number of missing items on the questionnaire (used as a proxy for data quality), although there was a non-significant excess in deaths with an unknown survival time.

Evidence for the employment/stress hypothesis is provided by the greater Monday excess found in men in the metaanalysis (assuming that men are more likely to be employed and exposed to greater stress on a Monday). Similarly the Monday excess in non-fatal events might be attributable to non-fatal events being more common among younger people, ${ }^{10}$ who are also more likely to be employed. If data were available for Moslem countries (where the working week begins on Saturday), or in Israel (where the working week begins on Sunday), they could be used to investigate the employment/stress hypothesis further.

The true cause of the Monday excess remains elusive, because of the absence of studies designed to investigate this phenomenon. We estimate that to find the cause would need a study of over 40000 events. This is based on a proportion of $(1 / 7+1 / 100)$ events on Monday and $1 / 7$ on other days of the week, and an $80 \%$ power and 5\% significance level. The study would need to record accurately each subject's alcohol consumption, employment (or stress) and other factors. Such a large study to examine an apparently small effect seems unjustified.

\section{ACKNOWLEDGEMENTS}

Thanks to Elsa Quagliotto for translating a journal article from Italian to English, and Lois Englberger for translating a journal article from German to English. Thanks also to Martin KcKee and Susana Sans for helpful comments on the manuscript. We thank the Hunter Valley Research Foundation for providing their weather data free of charge.

\section{Authors' affiliations}

A G Barnett, A J Dobson, School of Population Health, University of Queensland, Herston, Australia

Funding: this work was funded by the National Health and Medical Research Council of Australia (grant numbers 100954 and 252834).

Conflicts of interest: none declared.

\section{REFERENCES}

1 Arntz HR, Müller-Nordhorn J, Willich SN. Cold Monday mornings prove dangerous: epidemiology of sudden cardiac death. Curr Opin Crit Care 2001;7:139-44.

2 Cohen MC, Rohtla KM, Lavery CE, et al. Meta-analysis of the morning excess of acute myocardial infarction and sudden cardiac death. Am Heart J 1997;79:1512-15.

3 The Eurowinter Group. Cold exposure and winter mortality from ischaemic heart disease, cerebrovascular disease, respiratory disease, and all causes in warm and cold regions of Europe. Lancet 1997;349:1341-6.

4 Eng H, Mercer JB. Seasonal variations in mortality caused by cardiovascular diseases in Norway and Ireland. Am J Emerg Med 1998;5:89-95.

5 Willich SN, Lowel $\mathrm{H}$, Lewis $M$, et al. Weekly variation of acute myocardial infarction. Increased Monday risk in the working population. Circulation 1994;90:87-93.

6 Chenet L, Britton A, Kalediene R, et al. Daily variations in deaths in Lithuania: the possible contribution of binge drinking. Int J Epidemiol 2001;30:743-8.

7 McKee M, Britton A. The positive relationship between alcohol and heart disease in eastern Europe: potential physiological mechanisms. J R Soc Med 1998;91:402-7.

8 Barnett AG, Dobson A, for the WHO MONICA Project. Is the increase in coronary heart disease on Mondays an artifact of registration? Epidemiology 2004; 15:583-8.

9 Glasziou PP, Sanders SL. Investigating causes of heterogeneity in systematic reviews. Stat Med 2002;21:1503-11.

10 Tunstall-Pedoe $\mathrm{H}$, ed. MONICA monograph and multimedia sourcebook. Geneva: World Health Organisation, 2003.
11 Stroup DF, Berlin JA, Morton SC, et al. Meta-analysis of observational studies in epidemiology. J Am Stat Assoc 2000;283:2008-12.

12 Paul SD, Eagle KA, O'Gara PT. Weekly rhythm of acute myocardial infarction: are physicians more aggressive with thrombolysis after the weekend? [Abstract]. Circulation 1993;88(suppl I):509.

13 McElduff P, Dobson AJ. Case fatality after an acute cardiac event: the effect of smoking and alcohol consumption. J Clinical Epidemiol 2001;54:58-67.

14 Normand ST. Meta-analysis: formulating, evaluating, combining, and reporting. Stat Med 1999;18:321-59.

15 Spiegelhalter DJ, Thomas A, Best NG. Win BUGS version 1.2 user manual. London: Technical report, MRC Biostatistics Unit, 1999.

16 Higgins JPT, Thompson SG. Quantifying heterogeneity in a meta-analysis. Stat Med 2002;21:1539-58

17 Breiman L, Friedman JH, Olshen RA, et al. Classification and regression trees. Belmont, CA: Wadsworth International Group, 1984

18 Ihaka R, Gentleman RR. A Language for data analysis and graphics. Journal of Computational and Graphical Statistics 1996;5:299-314.

19 Pregibon D. Logistic regression diagnostics. Ann Stat 1981;9:705-24.

20 Myers A, Dewar HA. Circumstances attending 100 sudden deaths from coronary artery disease with coroner's necropsies. $\mathrm{Br}$ Heart $\mathrm{J}$ 1975;37:1133-43.

21 Rogot E, Fabsitz R, Feinleib M. Daily variation in USA mortality Am J Epidemiol 1976;103:198-211.

22 World Health Organisation. Myocardial infarction community registers. Public health in Europe no 5. Technical report. Geneva: World Health Organisation, 1976

23 Macfarlane A, White G. Deaths: the weekly cycle. Population Trends 1997:7:7-8.

24 Näyhä S. Short and medium-term variations in mortality in Finland. Scand J Soc Med 1980;21(suppl.):21-101.

25 Rabkin SW, Mathewson FAL, Tate RB. Chronobiology of cardiac sudden death in men. JAMA 1980;244:1357-8.

26 Beard MC, Fuster V, Elveback LR. Daily and seasonal variation in sudden cardiac death, Rochester, Minnesota, 1950-1975. Mayo Clin Proc 1982;57:704-6.

27 Massing W, Angermeyer MC. Myocardial infarction on various days of the week. Psychol Med 1985;15:851-7.

28 Pasqualetti P, Colantonio D, Casale R, et al. Cronobiologia della morte cardiaca improvvisa. Evidenza di una periodicita circadiana, circasettana e circannuale nella sua incidenza. (In Italian). Minerva Med 1990;81:391-8.

29 Nicolau GY, Haus E, Popescu M, et al. Circadian, weekly, and seasonal variations in cardiac mortality, blood pressure and catecholamine excretion. Chronobiol Int 1991;8:149-59.

30 Thompson DR, Pohl JEF, Sutton TW. Acute myocardial infarction and day of the week. Am J Cardiol 1992;69:266-7.

31 Bilora F, Vigna GB, Manfredini R, et al. Acute myocardial infarction incidence during the week: a chronobiological evaluation. Minerva Cardioangiol 1993:43:559-62.

32 Gnecchi-Ruscone T, Piccaluga E, Guzzetti S, et al. Morning and Monday: critical periods for the onset of acute myocardial infarction. the GISSI 2 study experience. Eur Heart J 1994;15:882-7.

33 Peters RW, Brooks MM, Zoble RG, et al. Chronobiology of acute myocardial infarction: cardiac arrhythmia suppression trial (CAST) experience. Am J Cardiol 1996;78:1198-201.

34 Spielberg C, Falkenhahn D, Willich SN, et al. Circadian, day-of-week, and seasonal variability in myocardial infarction: comparison between working and retired patients. Am Heart J 1996;132:579-85.

35 Genès N, Vaur L, Renault $M$, et al. Rythme circadien des infarctus du myocarde en France: résultats de l'étude USIK. (In French). Presse Med 1997;26:603-8.

36 Chenet L, McKee M, Leon D, et al. Alcohol and cardiovascular mortality in Moscow; new evidence of a causal association. J Epidemiol Community Health 1998; 52:772-4

37 Ku CS, Yang CY, Lee WJ, et al. Absence of a seasonal variation in myocardial infarction onset in a region without temperature extremes. Cardiology 1998:89:277-82.

38 Zhou RH, Xi B, Gao HQ, et al. Circadian and septadian variation in the occurrence of acute myocardial infarction in a Chinese population. Jpn Circ J 1998;62:190-2.

39 Peckova M, Fahrenbruch C, Cobb L, et al. Weekly and seasonal variation in the incidence of cardiac arrests. Am Heart J 1999;137:512-15.

40 Arntz HR, Willich SN, Schreiber C, et al. Diurnal, weekly and seasonal variation of sudden death. Eur Heart J 2000;21:315-20.

41 Evans C, Chalmers J, Capewell S, et al. "I don't like Mondays" - day of the week of coronary heart disease deaths in Scotland: study of routinely collected data. BMJ 2000:320:218-19.

42 Allegra JR, Cochrane DG, Allegra EM, et al. Calendar patterns in the occurrence of cardiac arrest. Am J Emerg Med 2002;20:513-17.

43 Australian Institute of Health and Welfare (AIHW). Seasonality of death. Technical report bulletin no 3. Canberra: AlHW, 2002.

44 Bleyer AJ, Russell GB, Satko SG. Sudden and cardiac death rates in hemodialysis patients. Kidney Int 1999;55:1553-9.

45 Peters RW, McQuillan S, Resnick SK, et al. Increased Monday incidence of life-threatening ventricular arrhythmias: experience with a third-generation implantable defibrillator. Circulation 1996:94:1346-9.

46 McKee M, Shkolnikov V, Leon DA. Alcohol is implicated in the fluctuations in cardiovascular disease in Russia since the 1980s. Ann Epidemiol 2001;11:1-6.

47 Keatinge WR. Death in heat waves. BMJ 2003;327:512-13. 